\title{
A PROSPECTIVE STUDY ON QUALITY OF LIFE IN PATIENTS WITH ARTHRITIS
}

\author{
POOJITHA DEVI G, SATHESH KUMAR S*
}

Department of Pharmacy Practice, School of Pharmaceutical Sciences, Vels Institute of Science, Technology and Advanced Studies (VITAS), Vels University, Chennai, Tamil Nadu, India. Email: sathesh2000@gmail.com

Received: 13 May 2016, Revised and Accepted: 24 May 2016

\section{ABSTRACT}

Objective: Patient counseling can scientifically improve the physical and mental symptoms of certain diseases that could be a relief to the patient. Non-pharmacological approaches could be an alternative to the drug therapy. Health issues affecting the quality of life (QoL) are to be studied to understand the patient's physical, mental, emotional, and social functioning.

Methods: The present study involves prospective analysis of QoL in men and women with arthritis. The methodology involves the collection and documentation of general information of the patient including personal history, family background, clinical findings, investigations, and medical illness associated with arthritis. Further, the QoL is documented using a specific questionnaire designed to assess the impact of arthritis and their complications.

Results: It can be seen that there is no significant changes in the physical and mental component score (MCS) in between the type of arthritis, but there is an extremely significant $(\mathrm{p}<0.05)$ values were obtained when compared between pre- and post-counseling phases of physical and MCS.

Conclusion: Patients counseling plays a major role in the management of signs and symptoms among patients with arthritis. The non-pharmacological method is also be used for the management of arthritis.

Keywords: Quality of life, Arthritis, Patient counseling, Questionnaire, Physical component score, Mental component score.

(C) 2016 The Authors. Published by Innovare Academic Sciences Pvt Ltd. This is an open access article under the CC BY license (http://creativecommons org/licenses/by/4. 0/) DOI: http://dx.doi.org/10.22159/ajpcr.2016.v9s2.12821

\section{INTRODUCTION}

Arthritis is a type of joint disorder which usually causes the inflammation in the joints [1]. The common types of arthritis include osteoarthritis (OA), rheumatoid arthritis (RA), septic arthritis (SA), and gouty arthritis [2]. Pain is the most important physical problem that is common with most people with arthritis [3]. OA is characterized by articular cartilage loss and hypertrophy of bone muscle [4]. RA is an inflammatory disease with the involvement of synovial joints [5]. The mental complications include depression and mood swings; these could lead to long-term depression, social anxiety disorder, etc. [6].

Counseling can improve patients' physical and mental symptoms that could be a relief to the patient [7]. Non-pharmacological approaches such as effective patient counseling could be a support for the drug therapy to improve the condition of the patients [8].

Health issues related quality of life (QoL) is studied to understand the physical, mental, emotional, and social functioning of patients. Arthritis is a chronic disease, and hence, monitoring the QoL would enable us to improve the patient perspective.

Maria et al. conducted a study on "assessing the functional status and QoL of patients with RA" and concluded that in the present study, it is patent the huge burden of RA on function and QoL of patients, generating a high level of unemployment. We stress the importance of the symptomatic control, especially pain. The assessment of the degree of functional impact by physicians and patients do not coincide, indicating the need of the evaluation of the treatment by the patient to improve results. We suggest that an aggressive and global focus on the patient should be from the onset of the disease on to help improve the vital and functional prognosis of our patients [9].

Whalley et al. conducted a study on "QoL in RA" and conducted. The measure is designed to provide valid and reliable information on QoL in
RA patients and how this is influenced by interventions. The measure will not allow comparisons between different diseases or lend itself to inclusion in pharmacoeconomic analyses at present. There is growing evidence that health utility and psychometric health status scales measure different aspects of health outcome [10].

The main aim of the study was to assess the QoL in patients with arthritis. The extent of impairment of health related QoL in patients with arthritis will be evaluated using the score obtained from a scientifically designed questionnaire.

\section{MATERIALS AND METHODS}

\section{Materials}

The study was carried out in a tertiary care hospital:

- $\quad$ Study period: 9 months

- Study Instrument: SF-12 questionnaire.

\section{Inclusion criteria}

i. In-patients diagnosed with arthritis

ii. Willing to participate in completing the simple questionnaire

iii. Patients of age $>20$ years.

\section{Exclusion criteria}

i. Patients of age above $<20$ years

ii. Patients with psychiatry complications

iii. Studies in those with previous traumas.

Methods

Study design

This method involves prospective analysis of QoL in men and women with arthritis. The study is carried out by the collection and documentation of general information of the patient including personal history, family background, clinical findings, investigations, and medical 
illness associated with arthritis. Further, QoL is documented using a specific questionnaire designed to assess the impact of arthritis and their complications. They are as follows.

\section{Study instrument}

SF-12 questionnaire

The SF- $12^{\circledR}$ Health Survey includes 12 questions from the SF- $36^{\circledR}$ Health Survey (Version 1). These include: 2 questions concerning physical functioning; 2 questions on role limitations because of physical health problems; 1 question on bodily pain; 1 question on general health perceptions; 1 question on vitality (energy/fatigue); 1 question on social functioning; 2 questions on role limitations because of emotional problems; 2 questions on general mental health (psychological distress and psychological well-being).

Finally, the documented questionnaire is evaluated for the outcome.

The study was conducted after obtaining informed consent from the patient. This study was approved by the Institutional Ethics Committee IEC/DOPV/2015/08

\section{RESULTS}

The following results were obtained when the data were collected from the patient.

Table 1 shows that out of selected 150 patient data, 68 patients (45\%) were male, and 82 patients (55\%) were female. In this study, it indicates that more number of females are affected with arthritis when compare to male.

Table 2 shows that out of selected 150 patients data, 4 patients (3\%) were in the age group of 20-30 years, 14 patients (9\%) were in the age group of 31-45 years, 32 patients (21\%) were in the age group of 4660 years, 52 patients $(64 \%)$ were in the age group of $61-75$ years, and 48 patients (32\%) were in the age group of $>76$ years; it indicates that the more number of people above 60 years are affected with arthritis when compared to other groups.

Table 3 shows that out of selected 150 patients, 64 patients (43\%) were suffering from OA (knee), 12 patients (8\%) were suffering from OA (hip), 33 patients (22\%) were suffering from RA, 15 patients (10\%) were suffering from $\mathrm{SA}$, and 26 patients $(17 \%)$ were suffering from gout arthritis; it indicates that more $\mathrm{OA}$ is the most common form of arthritis.

Table 4 shows that out of selected 150 patients, 72 patients (48\%) were having HTN, 94 patients (63\%) were having diabetes mellitus, 12 patients $(8 \%)$ were having BA, 4 patients $(3 \%)$ were having renal failure, 16 patients $(11 \%)$ were having hypothyroidism, and 20 patients (13\%) with no comorbidities; It indicates that diabetes is the most common among the comorbidities in arthritis.

A larger population of the patients (41\%) had been reported to suffer with the complication for the duration of 2-5 years, and this indicates that arthritis is chronic disease. The details of the duration for which patients were suffering are given in Table 5 .

Table 6 indicates that there are no significant changes in the physical and mental component score (MCS) in between the type of arthritis, but there is an extremely significant $(\mathrm{p}<0.05)$ values were obtained when compared between pre and post-counseling phases of the physical component score (PCS) and MCS.

Table 7 shows that there are significant changes in PCS in male and MCS in female.

\section{DISCUSSION}

Understanding the nature of RA and coping up with challenges of this condition can be done with the help of good education and counseling.
Table 1: Gender distribution

\begin{tabular}{lll}
\hline Serial number & Gender & Number of patients (n=150) (\%) \\
\hline 1 & Male & $68(45)$ \\
2 & Female & $82(55)$ \\
\hline
\end{tabular}

Table 2: Age distribution

\begin{tabular}{lll}
\hline Serial number & Age & Number of patients (n=150) (\%) \\
\hline 1 & $20-30$ & $04(3)$ \\
2 & $31-45$ & $14(9)$ \\
3 & $46-60$ & $32(21)$ \\
4 & $61-75$ & $52(34)$ \\
5 & $>76$ & $48(32)$ \\
\hline
\end{tabular}

Table 3: Prevalence of various types of arthritis in the study group

\begin{tabular}{lll}
\hline Serial number & Arthritis type & $\begin{array}{l}\text { Number of patients } \\
(\mathbf{n = 1 5 0 )}(\mathbf{\%})\end{array}$ \\
\hline 1 & Osteoarthritis (Knee) & $64(43)$ \\
2 & Osteoarthritis (Hip) & $12(8)$ \\
3 & Rheumatoid arthritis & $33(22)$ \\
4 & Septic arthritis & $15(10)$ \\
5 & Gouty arthritis & $26(17)$ \\
\hline
\end{tabular}

Table 4: Reported comorbidities in arthritis patients

\begin{tabular}{lll}
\hline Serial number & Comorbidities & Number of patients (\%) \\
\hline 1 & HTN & $72(48)$ \\
2 & DM & $94(63)$ \\
3 & BA & $12(8)$ \\
4 & Renal failure & $4(3)$ \\
5 & Hypothyroidism & $16(11)$ \\
6 & Nocomorbidities & $20(13)$ \\
\hline
\end{tabular}

BA: Bronchial asthma, DM: Diabetes mellitus, HTN: Hypertensions

Table 5: Duration of arthritis in the study group

\begin{tabular}{lll}
\hline Serial number & Year & Number of patients (\%) \\
\hline 1 & $<2$ & $37(25)$ \\
2 & $2-5$ & $61(41)$ \\
3 & $6-9$ & $39(26)$ \\
4 & 10 and above & $13(9)$ \\
\hline
\end{tabular}

The patient along with the health-care providers can work together to formulate a therapeutic plan and evaluate both the standard and alternative treatment options.

Certain measures such as biofeedback and cognitive therapy may help in controlling RA symptoms. Both the measures can help in improving one's self-esteem as well as the pain and disability. Some hospitals, clinics, and certain arthritis based organizations are offering programs on topics such as self-management skills, social support, and psychotherapy, which have been shown to reduce pain, depression, and disability in people suffering from arthritis and have also helped them to gain some control over their illness [11].

The results, in the above study, have shown that there are more female patients than male patients; similar results were seen on a study done by Bajraktari et al. [12].

As inferred from the current study, most of arthritis patients are above 60 years of age, and similar results were found on a study done by Pawlowska et al. [13]. 
Table 6: PCS and MCS in pre- and post-counseling of patients

\begin{tabular}{|c|c|c|c|c|c|c|}
\hline Serial number & Parameters & $\mathbf{O A}$ & RA & SA & Gout & $\mathbf{p}$ \\
\hline & PCS & & & & & \\
\hline 1 & Pre & $30.5 \pm 2.20$ & $41.32 \pm 1.36$ & $31.5 \pm 2.64$ & $37.9 \pm 4.12$ & 0.0987 \\
\hline 2 & Post & $40.2 \pm 1.19$ & $51.3 \pm 1.8$ & $56.3 \pm 1.56$ & $59.3 \pm 2.23$ & 0.0876 \\
\hline \multirow[t]{2}{*}{3} & $\mathrm{p}$ & $0.0032^{*}$ & $0.0029 *$ & $<0.0001^{*}$ & $0.0216^{*}$ & \\
\hline & MCS & & & & & \\
\hline 1 & Pre & $29.62 \pm 2.20$ & $38.17 \pm 2.20$ & $33.10 \pm 1.20$ & $31.40 \pm 1.92$ & 0.0589 \\
\hline 2 & Post & $39.3 \pm 2.21$ & $50.1 \pm 1.24$ & $46.1 \pm 2.25$ & $53.1 \pm 1.21$ & 0.0516 \\
\hline
\end{tabular}

*Indicates that the values are statistical significance. MCS: Mental component score, PCS: Physical component score. OA: Osteoarthritis, RA: Rheumatoid arthritis, SA: Septic arthritis

Table 7: Gender-wise impact-MCS and PCS in arthritis patient group

\begin{tabular}{|c|c|c|c|c|c|c|c|}
\hline \multirow[t]{2}{*}{ Serial number } & \multirow[t]{2}{*}{ Gender } & \multicolumn{3}{|l|}{ PCS } & \multicolumn{3}{|l|}{ MCS } \\
\hline & & Before & After & $\mathbf{p}$ & Before & After & $\mathbf{p}$ \\
\hline 1 & Male & $47.2 \pm 3.27$ & $54.3 \pm 3.17$ & $0.0049 *$ & $39.2 \pm 1.7$ & $44.2 \pm 1.11$ & 0.0814 \\
\hline 2 & Female & $41.3 \pm 2.21$ & $44.3 \pm 3.14$ & 0.0897 & $34.2 \pm 4.27$ & $41.66 \pm 3.19$ & $0.0348^{*}$ \\
\hline
\end{tabular}

MCS: Mental component score, PCS: Physical component score

OA is the most common form of arthritis, as concluded by my study was similar to the results shown by Breedveld [14].

This study shows that diabetes is the most common comorbidities in arthritis; these results were similar with the results reported by Dougados et al. [15].

It can be seen that there are no significant changes in the physical and MCS in between the types of arthritis, but the comparison of physical and MCS between pre- and post- counseling phases indicated significant ( $p<0.05)$ differences with various types of arthritis.

This study shows that there are significant differences in PCS in male and MCS in female.

\section{CONCULSION}

Patients counseling plays a major role in the management of signs and symptoms among patients with arthritis. The non-pharmacological method is also be used for the management of arthritis. We recommend for further research in the patient-oriented factors in managing arthritis.

\section{ACKNOWLEDGMENT}

The authors are hereby gratefully acknowledging Dr. Ishari K. Ganesh, Chancellor, Vels University, Chennai, for providing necessary support to carry out this study.

\section{REFERENCES}

1. Usenbo A, Kramer V, Young T, Musekiwa A. Prevalence of arthritis in Africa: A systematic review and meta-analysis. PLoS ONE 2015;10(8):e0133858, 1-19.

2. Reid MC, Shengelia R, Parker SJ. Pharmacologic management of osteoarthritis-related pain in older adults. Am J Nurs
2012;112 3 Suppl 1:S38-43.

3. Brosseau L, Welch V, Wells G, DeBie R, Gam A, Harman K, et al. Low level laser therapy (Classes I, II and III) for treating osteoarthritis. Cochrane Database Syst Rev 2004;3:CD002046.

4. Chabaud M, Garnero P, Dayer JM, Guerne PA, Fossiez F, Miossec P. Contribution of interleukin 17 to synovium matrix destruction in rheumatoid arthritis. Cytokine 2000;12(7):1092-9.

5. Kirkley A, Birmingham TB, Litchfield RB, Giffin JR, Willits KR, Wong CJ, et al. A randomized trial of arthroscopic surgery for osteoarthritis of the knee. N Engl J Med 2008;359(11):1097-107.

6. Chan KW, Felson DT, Yood RA, Walker AM. The lag time between onset of symptoms and diagnosis of rheumatoid arthritis. Arthritis Rheum 1994;37(6):814-20.

7. Bridges PS. Prehistoric arthritis in the Americas. Annu Rev Anthropol 1992;21:67-91.

8. Won HY, Lee JA, Park ZS, Song JS, Kim HY, Jang SM, et al. Prominent bone loss mediated by RANKL and IL-17 produced by CD4 T cells in TallyHo/JngJ mice. PLoS One 2011;6(3):e18168.

9. Vanitallie TB. Gout: Epitome of painful arthritis. Metabolism 2010;59 Suppl 1:S32-6.

10. Corbacho MI, Dapueto JJ. Assessing the functional status and quality of life of patients with rheumatoid arthritis. Rev Bras Reumatol 2010;50(1):31-43.

11. Whalley D, Mckenna SP, de Jong Z, Van der Heijde D. Quality of life in rheumatoid arthritis. Br J Rheumatol 1997;36(8):884-8.

12. Bajraktari IH, Teuta BÇ, Vjollca SM, Bajraktari H, Saiti V, Krasniqi B, et al. Demographic features of patients with rheumatoid arthritis in Kosovo. Med Arch 2014;68(6):407-10.

13. Pawlowska J, Smolenska Z, Daca A, Witkowski JM, Bryl E. Older age of rheumatoid arthritis onset is associated with higher activation status of peripheral blood $\mathrm{CD} 4^{+} \mathrm{T}$ cells and disease activity. Clin Exp Immunol 2011;163(2):157-64.

14. Breedveld FC. Osteoarthritis - The impact of a serious disease. Rheumatology (Oxford) 2004;43 Suppl 1:i4-8.

15. Dougados M, Soubrier M, Antunez A, Balint P, Balsa A, Buch MH, et al. Prevalence of comorbidities in rheumatoid arthritis and evaluation of their monitoring: Results of an international, cross-sectional study (COMORA). Ann Rheum Dis 2014;73(1):62-8. 